\title{
A Pilot Study of Brief Group Therapies for Preschool Children: Parent Training vs Group Play Therapy vs Project Group
}

\author{
William S. Evans, Jr., M.D. \\ Eisenhower Army Medical Center, Fort Gordon Georgia
}

Susan A. Black, M.D.

Eisenhower Medical Center, Fort Gordon, Georgia

Follow this and additional works at: https://jdc.jefferson.edu/jeffjpsychiatry

Part of the Psychiatry Commons

Let us know how access to this document benefits you

\section{Recommended Citation}

Evans, Jr., M.D., William S. and Black, M.D., Susan A. (1989) "A Pilot Study of Brief Group Therapies for Preschool Children: Parent Training vs Group Play Therapy vs Project Group," Jefferson Journal of Psychiatry. Vol. 7 : Iss. 2 , Article 8.

DOI: https://doi.org/10.29046/JJP.007.2.006

Available at: https://jdc.jefferson.edu/jeffjpsychiatry/vol7/iss2/8

This Article is brought to you for free and open access by the Jefferson Digital Commons. The Jefferson Digital Commons is a service of Thomas Jefferson University's Center for Teaching and Learning (CTL). The Commons is a showcase for Jefferson books and journals, peer-reviewed scholarly publications, unique historical collections from the University archives, and teaching tools. The Jefferson Digital Commons allows researchers and interested readers anywhere in the world to learn about and keep up to date with Jefferson scholarship. This article has been accepted for inclusion in Jefferson Journal of Psychiatry by an authorized administrator of the Jefferson Digital Commons. For more information, please contact: JeffersonDigitalCommons@jefferson.edu. 


\title{
A Pilot Study of Brief Group Therapies for Preschool Children: Parent Training vs Group Play Therapy vs Project Group
}

\author{
William S. Evans, Jr., M.D. \\ Susan A. Black, M.D.
}

\section{INTRODUCTION}

The optimum modality for treating preschool age children with behavioral and emotional problems is uncertain. One study showed that children with good ego strength respond to psychotherapy independent of whether it is group or individual psychotherapy, provided that a minimum period of psychotherapy occurs (Novick, 1965). The literature has demonstrated that parent training, individual play therapy, and group therapy are all effective modes of treatment with children (Axline, 1969; Moreland, et al, 1983; Pescosolido \& Petrella, 1986). Due to the limited psychiatric resources in the military setting and increasing demand for service, the option for individual therapy may be restricted to specific neurotic clinical diagnoses. We studied the efficacy of shortterm group treatment applicable to behaviorally and emotionally disordered children, ages 4 through 6 years. In a review of various group treatments, the number of sessions ranged from 10 to 15 (Abramowitz, 1976). In another study, the mean number of hours needed to produce therapeutic benefits in parent training was 9.5 (Forehand, et al, 1979). All of the treatments to be considered are structured around a group principal to allow more patients to be treated for the same clinician time expenditure. Our study compared parent training, to group play therapy, and a project group on a population of behaviorally or emotionally disordered children, ages 4 to 6 . The groups themselves ran for eight weeks, 75 minutes each week, along with 50 -minute pre and post sessions with each set of parents. Total clinical time was approximately 24 hours per group for both therapists.

Review articles on studies of parent training of preschool age children demonstrate that it is an effective method of treating disturbed children. (Berkowitz, Graziano, 1972, Johnson, Katz, 1973, Moreland, et al, 1983). The goal is to train the parents to be the therapist for their children's behavior. It is felt that parents constitute an inexpensive, continuous treatment resource which is able to augment existing therapeutic manpower capabilities (Johnson \& Katz, 1973). Parent training has been used in a wide variety of disorders including conduct problems, oppositional defiant traits, school phobia, encopresis, enuresis, psychosis, and mental retardation. Webster-Stratton working with the par- 
ents of conduct disordered children, demonstrated that group parent training was as effective as working individually with parents (Webster-Stratton, 1984). It has also been shown that significant changes in one aspect of the family system can lead to improvement in the entire system, and that therapy need not deal with every problem since through generalization, a whole chain of improvement may occur. (Patterson, et al, 1970). In another study (Webster-Stratton, 1985), parent training produced improvement in the children's behavior at a one-year followup.

In a review of preschool group therapy literature, one study concluded that group psychotherapy for children of this age group is both clearly valuable and highly indicated as a treatment modality for treating disturbed children. (Pescosolido \& Petrella, D. 1986). The group activities encourage peer interactions and teach appropriate social skills in an atmosphere of acceptance, nonretaliation, and nourishment in the service of encouraging benign and guided regression (Frank \& Zilbach, J. 1968). With group play therapy, a significant increase in peer interaction and decrease in disruptive behaviors is noted (Twerdosz, et al, 1983). In another study, the group itself and not the selection of children to put into a group was the critical outcome variable (Johnson \& Katz, 1973). In all, the literature is supportive of the statement that play group therapy is beneficial for a wide variety of behaviorally or emotionally disordered children.

In the literature there is no reference to the use of a project group alone as a treatment modality. References are made to activity groups with the use of arts and crafts along with the emphasis of group cohesion, emotional engagement, and interpretations as being beneficial to behaviorally disordered children. (Axline, 1969; Ginott, 1961; Slavson, 1943). It is uncertain whether it is the project portion of the exercise, with commonalty of a concrete task, group cohesion, and tangible products which the children can take home that are responsible for therapeutic changes (Pescosolido \& Petrella, 1986), or the therapist's on the spot interpretation, modifying and verbalizing alternative behaviors that is the therapeutic tool (Plank, (1978). In our study, we looked independently at the project portion of the group, thus allowing a clearer distinction from our play therapy group. The project group lacked the psychotherapeutic interventions that are present in both the group play therapy and classically described activity groups.

The use of food has proved to be an integral part of both play therapy, group, and "activity" groups. Food has been taken to be a tangible sign of nurturance by the therapist (Pescosolido \& Petrella, 1986), as well as a time to cool down, allowing adults and children a time to share experiences before the ending of the group (Steward, et al, 1986).

To date, there has been no comparison between parental training and group therapies, whether group play therapy or activity group. What we did was to compare the treatment modes and to closely control the activity group which we termed a project group. 


\section{METHOD}

Subjects

The pilot study was composed of 23 behaviorally or emotionally disordered children, ages 4 through 6 . The subjects were initially referred to the Child and Adolescent Psychiatry Service, Tripler Army Medical Center, by their parents, the Department of Education, or Developmental Pediatrics. The screening evaluation consisted of either of two possibilities: 1) a half-hour history gathering along with a three-hour Child Study Group evaluation; or 2) a one- or two-hour triage evaluation. After the screening evaluation, the children who were actually felt to have behavioral or emotional disorders, were referred to the study. Normal children without adaptive difficulties and children with Pervasive Developmental Disorders, and Mental Retardation (DSM-III-R 1987) were excluded from the study. (See Table 1 for initial DSM-III-R diagnostic impressions). There were 14 boys and 2 girls completing the study with an overall mean age of 4.7 years. Eleven of the children came from intact families, three had one step-parent, one had a single parent, and one was adopted. The mean maternal age was 28.1 and the mean paternal age was 29.8.

\section{Dependent Measures}

Achenbach Child Behavior Checklist (CBCL): The CBCL is designed to be filled out by parents. It measures, in a standardized format, the behavioral problems and social competencies of children age 4 through 16. The Social Competence section yields three scales which are Activities, Social Behavior, and School Behavior. Since School Behavior is not measured in 4 year olds, that scale was not used. The Behavior Problems section yields nine scales which may vary slightly depending on age or sex of patient. In our study we used the scales held

TABLE 1.

Summary of Diagnostic Impressions

\begin{tabular}{lc}
\hline Diagnosis & Frequency \\
\hline AXIS I & 7 \\
Oppositional Defiant Disorder & 6 \\
Adjustment Disorder & 5 \\
Parent-Child Problems & 3 \\
Attention Deficit Hyperactivity Disorder & 2 \\
Funtional Enuresis/Encopresis & 2 \\
Separation Anxiety/Avoidant Disorder & 1 \\
Dysthymic Disorder & \\
AXIS II & 3 \\
Developmental Articulation Disorder & 1 \\
Developmental Expressive Language Disorder & \\
\hline
\end{tabular}


in common by our subjects which included: Somatic, Depressed, Schizoid, Social Withdrawal, and Aggressive behaviors. The Behavior Problems section also yields two broad-based groupings called Internalizing and Externalizing. Internalizing corresponds to fearful, inhibited, overcontrolled behaviors, while externalizing corresponds to aggressive, antisocial and undercontrolled behaviors.

Conners Parent Symptom Questionnaire (PSQ): This is a 45 -item scale completed by the parent. It yields the following subscales: Conduct Problems, Learning Problems, Psychosomatic Problems, Impulsivity-Hyperactivity, Anxiety, and Hyperactivity indexes.

Home-Situations Questionnaire (HSQ): This scale deals primarily with the settings in which behavior problems occur. It consists of 16 different problem situations and parents are asked to indicate if there is a problem in each setting and if so, rate the severity on a scale of $0-9$. The HSQ is scored for number of problem settings and for mean severity. Norms are available for boys and girls age $4-11$.

Procedure

The parents of the subjects identified were first seen individually to explain the research protocol and have their questions answered. The first eight subjects identified were scheduled for the Parent Training. The next eight were assigned to the Group Play Therapy, and the last seven were assigned to the Project Group. All participants were required to complete the dependent measures previously outlined, prior to the first group and at the completion of the treatment.

Due to their voluntary status, no coercive methods were used to ensure participation. Parents were called and encouraged to attend the upcoming sessions, and only after four misses were they dropped from the study. If the subject had completed the treatment, two phone contacts and at least one written notice were sent prior to subject's withdrawal from the study.

Due to the lack of availability of participants, the groups ran sequentially rather than simultaneously. The Parent Training Group began first; the Group Play Therapy began on week 5 of the Parent Group; the Project Group began on week 6 of the Play Group. All groups ran for approximately 75 minutes, for eight consecutive weeks. Make-up sessions were offered for parents who missed a portion of the Parent Training, but no make-ups were offered for either the Play or Project Group. (See Table 2 for attendance of subjects). Both investigator and associate investigator were present for all groups. After the completion of the treatment period, the parents of the subjects were seen for a second individual session to monitor progress, give feedback, and answer all questions. The content of the groups were as follows:

Parent Training (Group 1): The Parent Training classes were structured around eight sessions similar to the format used by (Barkley, 1981). The weekly sessions were as follows: 
TABLE 2.

Session Absences

\begin{tabular}{|c|c|c|c|c|c|c|c|c|c|c|}
\hline \multirow[b]{2}{*}{ No. } & \multicolumn{8}{|c|}{ Sessions } & \multirow{2}{*}{$\begin{array}{c}\text { Total } \\
\text { Missed }\end{array}$} & \\
\hline & 1 & 2 & 3 & 4 & 5 & 6 & 7 & 8 & & \\
\hline 1 & & & & & & $\mathrm{X}$ & $\mathrm{X}$ & $\mathrm{X}$ & 3 & \\
\hline 2 & & & & & & & & & 2 & \\
\hline 3 & & & & $\mathrm{X}$ & & $\mathrm{X}$ & & $\mathrm{X}$ & 3 & Group \\
\hline 4 & & & & & $\mathrm{X}$ & & $\mathrm{X}$ & & 2 & 1 \\
\hline \multirow[t]{2}{*}{5} & & & $\mathrm{X}$ & & & $\mathrm{X}$ & $\mathrm{X}$ & & 3 & \\
\hline & \multicolumn{8}{|c|}{$* * * * * * * * * * * * * * * * * * * * * * * * * * * * * * * * * * * * * * * * * * * * * * * * * * *$} & & \\
\hline 6 & & $\mathrm{X}$ & & & $\mathrm{X}$ & & & & 2 & \\
\hline 7 & & & & $\mathrm{X}$ & & $\mathrm{X}$ & & & 2 & Group \\
\hline 8 & & & $\mathrm{X}$ & & $\mathrm{X}$ & & $\mathrm{X}$ & $\mathrm{X}$ & 4 & 2 \\
\hline 9 & $\mathrm{X}$ & $\mathrm{X}$ & $\mathrm{X}$ & $\mathrm{X}$ & & & & & 4 & \\
\hline 10 & & & $\mathrm{X}$ & & & & $\mathrm{X}$ & & 2 & \\
\hline \multirow[t]{2}{*}{11} & & & & & & & $\mathrm{X}$ & & 1 & \\
\hline & ** & k** & *** & *** & $* * *$ & $* * *$ & $k * *$ & ** & & \\
\hline 12 & & & & $\mathrm{X}$ & & & & & 1 & \\
\hline 13 & & & $\mathrm{X}$ & & & & & & 1 & Group \\
\hline 14 & & & & & & & & & 0 & 3 \\
\hline 15 & & & & & & & & & 0 & \\
\hline 16 & & & & & & & & & 0 & \\
\hline
\end{tabular}

Key: $\mathrm{X}=$ missed session

Week 1-introductions, special time;

Week 2-review of special time; use of proper commands;

Week 3-review of proper commands, beginning the token system;

Week 4-completion of the token system;

Week 5-review of the token system; use of time-outs at home;

Week 6 -time-outs for multiple occasions, use of time-outs in public places;

Week 7-discussion of future misbehavior;

Week 8-summary of classes, questions and answers.

When a session was missed by the parents, they were contacted by phone and seen for a catch-up session prior to the next week's group. It was felt that the parents needed the skills from one group session to proceed to the next. The goal of the approach was to teach the parents a positive way of relating to their children. Attempts to discuss and resolve individual subjects' problems within that frame of reference were made.

Group Play Therapy (Group 2): The sessions were divided into two parts. The first portion, the Play Therapy portion, lasted for 60 minutes followed by a 15-minute cookie and juice period. The therapeutic tools available included: white paper, markers, doll house with furniture, two complete doll house families, two sets of Barbie and Ken, monster finger puppets, school bus, ambulance, cars, and trucks, two doctor's kits, modeling clay, and nurf balls. The room was set up the same each week, with a table and chairs in the middle, and 
the toys in the periphery. All toys remained consistent from session to session except the modeling clay which was deleted after week five, secondary to excessive regression and mess. The goal of the play sessions was to allow the children free choice of therapeutic themes and material. Attempts to allow individual exploration and working through of personal conflicts were fostered. The only limits that were set centered around prevention of physical aggression towards person or property. The cookies and juice served as a time to calm down and reintegrate. During this period, a discussion of the group content took place. The refreshments also proved a time for the members to get to know each other and share mutual experiences. This period gave the facilitators a chance to reinforce prosocial behavior and at times, interpret interpersonal conflicts.

Project Group (Group 3): The sessions were divided into two parts. The first portion, the project portion, lasted for 60 minutes followed by a 15 -minute cookie and juice period. Each group was highly structured with all members working towards completion of the project; no free play was allowed. Throughout the session, the subjects were assisted in completing their projects, and redirected when off tasks. A new project was undertaken each week, and was decided upon the prior week by the group during the refreshment portion. The projects were as follows:

Week 1-self portrait mural using markers and construction paper;

Week 2-tempra painting of a christmas tree with presents;

Week 3-Santa Claus puppets;

Week 4-nature mural with ocean, land, and premade animals;

Week 5-monster masks made out of shopping bags; string and construction paper;

Week 6-tempra painting of a train;

Week 7-monster puppets made with lunch bags;

Week 8 -self portraits decorated and placed on a mural.

All projects were accompanied by group clean-up, at the end of which cookies and juice took place. During refreshments, pride was taken in the just completed projects and plans for the next week's project were begun. No attempts for individual exploration were made.

Sixty minutes of each session were videotaped with a camera placed in the corner of the room. In general, the camera was left stationary and no attempts were made to redirect the camera to specific activities. The videos were used by investigator and supervisors for review of the group's progress and discussion. The videos were not used to modify our therapeutic interventions for specific subjects, but more of a steering mechanism for the group itself.

\section{RESULTS}

The Parent Training Group lost three subjects: one subject that never attended any groups; one subject that attended only one group and was dropped 
from the study; one subject that completed the treatment, but failed to complete the post treatment measures.

The Group Play Therapy lost two subjects: one subject that never attended any groups, and one subject that completed the treatment, but failed to complete the post treatment measures.

The Project Group lost two subjects: one subject that never attended any groups, and one subject that attended only one group and was dropped from the study.

The data was analyzed using the Statistical Package for the Social Sciences (SPSS). The first analysis was an ANOVA of the overall post-test results by group, using the pre-test results as a covariate. The covariates of the group proved to be statistically different on 11 of the 16 variables examined. The variables which proved similar included the Social Withdrawal, Social, and Activities scales of the CBCL; the number of problems on the HSQ; and the Impulsivity/Hyperactivity scale of the PSQ. There were no statistically significant post-test changes in any of the 16 variables examined between groups.

Since there were no significant post-test differences between the groups, we next performed a t test on the pre/post-test scores to determine if the interventions as a whole were effective. The Internalizing scale of the CBCL showed a positive trend ( $\mathrm{t}$ score $=.075$ ) while the other 15 variables were nonsignificant. We next examined each group individually using the t test. The Parent Training Group (Group 1) were not statistically significant on any dependent variable. The Play Therapy Group (Group 2) showed two significant changes: 1) Social Withdrawal CBCL $(\mathrm{P}<.05)$; and 2$)$ Internalizing scale CBCL $(\mathrm{P}<.05)$. There were three variables with positive trends: Aggressive scale of the CBCL $(\mathrm{P}=.081)$. Externalizing scale of the CBCL $(\mathrm{P}=.097)$, mean severity of the HSQ (P = .082). The Project Group (Group 3) only had positive trends on the Somatic scale of the CBCL $(\mathrm{P}=.099)$, and the Hyperactivity Index of the PSQ $(\mathrm{P}=.08)$.

In general, there was a significant problem with attendance. Group 1 had a total of 15 missed sessions, with a mean of 2.5 per subject. Group 2 had 19 missed sessions, with a mean of 2.7 per subject. Group 3 had 2 missed sessions, with a mean of 0.4 per subject. (See Table 3 ). Because of the extent of missed sessions, the question was raised whether the number of absences adversely affected subjects' outcome. An ANOVA of the overall post-test results by number of sessions missed using the pre test results as a covariate was performed. One variable showed a significant relationship with missed sessions; the number of problems of the HSQ scale $(P<.05)$. To further look at the effects of missed sessions, linear correlations were performed between the number of missed sessions and the change in the pre/post variables. One variable proved to have a positive linear correlation; the number of problems of the HSQ scale $(R=.6137$ $\mathrm{P}<.01)$.

The last independent variable examined was the effect of primary diagnosis on overall outcome. (See Table 1). An ANOVA of the overall post test results by 
TABLE 3.

Statistics

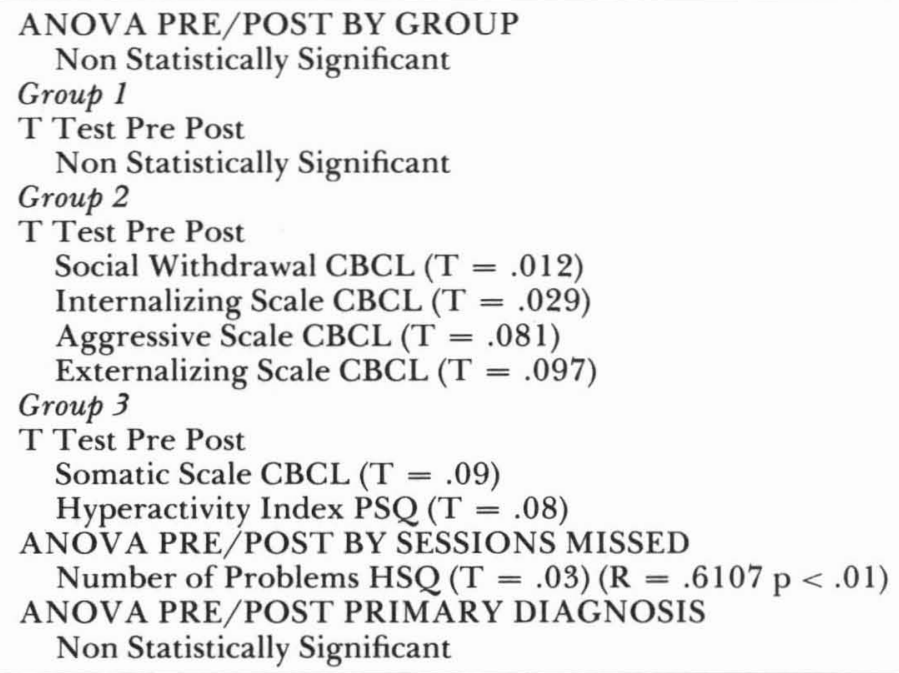

primary diagnosis using the pre test results as a covariate was performed. No significant differences were found.

\section{DISCUSSION}

The subjects were initially planned to all be collected, matched, then randomly assigned to the three groups. Due to the paucity of referrals, the initial subject pool was not able to be gathered. Instead the first eight referrals were placed in the Parent Training Group, the next eight in the Play Therapy Group, and the last seven referrals in the Project Group. By assigning the first eight subjects to Group 1, the next eight to Group 2, and the last seven to Group 3, it was assumed that the groups would end up with similar pre-test scores. This assumption proved false. In three sets of ANOVA's, the covariant proved significantly different in almost every case. The exact reason for the difference is uncertain. One explanation is that the difference was due to the time of selection: Group 1 over summer vacation, Group 2 shortly after school started, and Group 3 two months into school. Since the majority of the subjects were not in school, the time of referral should not have made a difference, but it remains our formost explanation to date. The other possibility remains that the small $\mathrm{N}$ of our study prevented the randomization that larger N's would have allowed.

That the groups were not equal to begin with, complicated by the small group sizes $(\mathrm{N}=5,6,5)$ made any changes statistically difficult to demonstrate. When the groups were examined individually we found several positive trends. 
The two statistically significant variables, social withdrawal CBCL, and internalizing scale CBCL occurred in the Group Play therapy. One would predict that if the therapy groups had therapeutic responses, it would be in the area of socialization, as did our Play Therapy group. What we cannot explain is why there was improvement in the Play Therapy group for these parameters, but not for the Project group unless we conclude that the very difference in the groups was the significant factor. The Play Therapy group was built around a nonstructured, free expressive, interpretive format which may have allowed individual growth, where the structure of the Project group may have prevented this. Another factor that was different between the two therapy groups was mean age. $\left(\right.$ Play Therapy $y_{\mathrm{x}}=5.0$, Project Group $\mathrm{x}_{\mathrm{x}}=4.4$ ). One study felt that the minimal age for group cohesion and personal growth was 5. (Merkin, M., Brusiloff, P. 1981). The younger age of the Project group may have prevented maximal benefit from their group experience.

Attendance proved a major problem in Group 1 and Group 2 and even when the parents attended training, their compliance with recommendations was not optimal. Several studies revealed similar problems with attendance and compliance (Firestone \& Witt, 1982; Firestone, et al, 1986). We further examined the number of sessions missed and the effects on outcome. It was clear that both Group 1 and Group 2 had poorer attendance than Group 3. The best attendance occurred in the Project group which was much easier to understand for the parents than the Play Therapy group. It is often difficult to adequately explain to parents what occurs in play therapy, but when you discuss projects and activities they not only understand but take considerable pride in the project their child did each week. The reason for poor compliance with the parenting group is uncertain, but in comparison with a parenting group for ADHD children run at our institution, compliance rates are similar. When the missed sessions are looked at statistically through an ANOVA, there appeared to be no significant difference in outcome. The number of problems in the HSQ also increased with missed sessions but in the face of variable mean severity, no clinical relevance can be placed on the correlation.

After sessions 4 and 8, the parents were asked how their child was doing and what changes, if any, they had noted. In general, the parents were positive in their reports. What we noted though, was that their post tests did not necessarily reflect the improvements that the parents had verbalized. What was clear from the start was that many of the measures (the CBCL in particular), did not reflect abnormal scores even in the face of a clinically dysfunctional child. If the CBCL was used alone as an indication of dysfunction, none of the subjects would have needed treatment. The HSQ clearly identified problem areas, but the post tests proved highly variable, often with an inverse relation between the number of problems and mean severity.

The question always arises as to the duration of treatment. For the Parent Training group, the eight 75-minute sessions should have been more than adequate (Forehand, et al, 1979), but the number of sessions for Play Therapy 
and the Project group may not have been enough. In one study, ten Activity groups proved inadequate, but after 20 sessions, therapeutic responses were noted (Novich, 1965). Another question that arises is group selection and the effect on treatment outcome. Our group excluded only children with Pervasive Developmental Disorder and Mental Retardation. Perhaps the remaining categories of dysfunctional children cannot all benefit from the short-term treatments offered. There are numerous studies proving the lack of effectiveness in lower socioeconomic families, families with social stress or marital discord (Dumas, 1984; Dumas, Albin, 1986; Firestone, \& Witt, 1982; Moreland, et al, 1983). It would seem appropriate to screen children who could specifically benefit from brief treatment and refer the more problematic cases requiring extended treatment to alternative sources. One study recommended the use of preliminary diagnostic group sessions by the group facilitators to further screen children prior to group entry (Haizlip, et al, 1975).

\section{CONCLUSION}

In looking back over the study, the small sample size and the vastly different nature of the groups was its major downfall. The dependent measures, although revealing a lot of information, clearly were not sensitive enough to depict our population of clinically disordered children. Measures more specifically tailored for socialization, and social skill acquisition may have proved more beneficial. The use of measures not reliant on parent reporting may alone prove beneficial. In reviewing the results one gets the impression that the Group Play Therapy may be the more effective treatment modality for behaviorally or emotionally disordered children (4-6 years old). Two statistically significant variables, social withdrawn CBCL, and internalizing scale CBCL occurred in the Group Play Therapy along with several near significant results. One would predict that if the Play Therapy group had a therapeutic response, it would be in the area of socialization. In summary our pilot study although not definitive, would lead one to believe that Group Play Therapy is the optimum treatment modality. Many of the problems in the study were outlined and alternate solutions offered. It is hoped that in the future a better controlled study can be performed that will clearly delineate the optimum treatment for behaviorally and emotionally disordered children ages 4 to 6 .

\section{BIBLIOGRAPHY}

Abramowitz CV: The effectiveness of group psychotherapy with children. Arch Gen Psychiatry 33:320-326, 1976

Axline VM: Play Therapy. Ballentine Books, Inc, 1969

Barklay RA: A Manual for Training Parents of Behavior Children. Guilford Press, 1981 Berkowitz BP, Graziano AM: Training parents as behavior therapists: A review. Behav

Res and Therapy 10:297-317, 1972 
Critchley DL: Therapeutic group work with abused preschool children. Perspective in Psychiatric Care XX(2):79-85, 1982

Dumas JE: Interactional correlates of treatment outcome in behavioral parent training. Journal of Counseling and Clinical Psychiatry, 52(6):946-954, 1984

Dumas JE, Albin JB: Parent training outcome: Does active parental involvement matter? Behav Res Ther 24(2):227-230, 1986

Firestone P, Witt J: Characteristics of families completing and prematurely discontinuing a behavioral parent-training program. Journal of Pediatric Psychology 7(2):209-222, 1982

Firestone P, et al: Vicissitudes of follow-up studies: Differential effects of parent training and stimulant medication with hyperactives. American Journal Orthopsychiatry 56(2): 184-194, 1986

Forehand R, et al: Parent behavioral training to modify child noncompliance. Behavior Modification January 3:25, 1979

Ginott HG: Group Psychotherapy with Children. New York, McGraw Hill Book Company, 1961

Haizlip T, et al: Issues in developing psychotherapy groups for preschool children in outpatient clinics. Am J Psychiatry 132:10, 1061-1063, 1975

Johnson CA, Katz RC: Using parents as change agents for their children: A review. J Child Psychol Psychiat 14:181-200, 1973

Merkin M, Brusiloff P: Group therapy with preschool children. Family and Child Mental Health Journal 7(1):55-63, 1981

Moreland JR, et al: Parents as therapists: A review of the behavior therapy parent training literature, 1975-1981. Behavior Modification 6(2):250-276, 1983

Novich JI: Comparison between short-term group and individual psychotherapy in effecting change in nondesirable behavior in children. Int. J. Group Psychotherapy, 15: $366-373,1965$

Patterson GR, Cobb JA and Ray RS: A social engineering technology for retraining aggressive boys in Georgia Symposium in Experimental Clinical Psychology Vol II, edited by Adams $\mathrm{H}$ and Unihel L. Oxford, Perganow Press, 1970

Pescosolido FJ, Petrella D: The development, process, and evaluation of group psychotherapy with sexually abused preschool girls. Int J Group Psychother 36(3):447-468, 1986

Plenk AM: Activity group therapy for emotionally disturbed preschool children. Behavioral Disorders 3(3):210-218, 1978

Steward M, et al: Group therapy: A treatment of choice for young victims of child abuse. Int J Group Psychotherapy 36(2):261-277, 1986

Twardosz S, Nordquist VM, Simon R, et al: The effect of group affection activities on the interaction of socially isolated children. Analysis and Intervention in Developmental Disabilities 3:311-338, 1983

Webster-Stratton C: Randomized trial of two parent-training programs for families with conduct disordered children. J of Consulting and Clinical Psychol 52(4):666-678, 1984

Webster-Stratton C: The effects of father involvement in parent training for conduct problem children. J Child Psychol Psychiat 26(5):801-810, 1985 